\title{
Surgical Roles for Spinal Involvement of Hematological Malignancies
}

\author{
Sang-Il Kim, M.D., Young-Hoon Kim, M.D., Ph.D., Kee-Yong Ha, M.D., Ph.D., Jae-Won Lee, M.D., Jin-Woo Lee, M.D. \\ Department of Orthopaedic Surgery, Seoul St. Mary's Hospital, College of Medicine, The Catholic University of Korea, Seoul, Korea
}

Objective : Patients with hematological malignancies frequently encounter spine-related symptoms, which are caused by disease itself or process of treatment. However, there is still lack of knowledge on their epidemiology and clinical courses. The purpose of this article is to review clinical presentations and surgical results for spinal involvement of hematologic malignancies.

Methods : From January 2011 to September 2014, 195 patients (98 males and 97 females) suffering from hematological malignancies combined with spinal problems were retrospectively analyzed for clinical and radiological characteristics and their clinical results.

Results : The most common diagnosis of hematological malignancy was multiple myeloma ( 96 patients, 49.7\%), followed by chronic myeloid leukemia (30, 15.2\%), acute myeloid leukemia (22, 11.2\%), and lymphoma (15, 7.56\%). The major presenting symptoms were mechanical axial pain $(132,67.7 \%)$ resulting from pathologic fractures, and followed by radiating pain (49, 25.1\%). Progressive neurologic deficits were noted in 15 patients (7.7\%), which revealed as cord compression by epidural mass or compressive myelopathy combined with pathologic fractures. Reconstructive surgery for neurologic compromise was done in 16 patients. Even though surgical intervention was useful for early paralysis (Frankel grade D or E), neurologic recovery was not satisfactory for the progressed paralysis (Frankel grade A or B).

Conclusion : Hematological malignancies may cause various spinal problems related to disease progression or consequences of treatments. Conservative and palliative treatments are mainstay for these lesions. However, timely surgical interventions should be considered for the cases of pathologic fractures with progressive neurologic compromise.

Key Words : Hematologic neoplasms · Spine · Fractures, Bone · Spinal cord injuries.

\section{INTRODUCTION}

Secondary bone tumors originate from various organs. Prostate, breast, lung, kidney, and thyroid cancers account for $80 \%$ of all skeletal metastases ${ }^{1,10)}$. Hematological malignancies, although the incidence is less than that of solid malignant tumors, also frequently affect the skeletal system. Among these skeletal events, the spine is one of the most commonly involved site. In cases of involving spinal column by hematological malignancies, patients show various clinical manifestations including bone pain syndrome, pathological fractures, recurrent infection, or neurologic compromise ${ }^{15-17)}$. These complications bring patients with hematological malignancy to spine department and spinal lesions usually need a multi-

- Received : November 1, 2016 • Revised : January 7, 2017 •Accepted : February 13, 2017

- Address for reprints : Young-Hoon Kim, M.D., Ph.D.

Department of Orthopedic Surgery, Seoul St. Mary's Hospital, College of Medicine, The Catholic University of Korea, 222 Banpo-daero, Seocho-gu, Seoul 06591, Korea Tel : +82-2-2258-6118, Fax : +82-2-535-9834, E-mail : boscoa@catholic.ac.kr

This is an Open Access article distributed under the terms of the Creative Commons Attribution Non-Commercial License (http://creativecommons.org/licenses/by-nc/4.0) which permits unrestricted non-commercial use, distribution, and reproduction in any medium, provided the original work is properly cited. 
modal strategy including surgery, chemotherapy, and radiation therapy in addition to the primary medical treatment for the hematological disease. These involvements frequently result in disability and morbidity leading to increased anxiety and socio-economical cost.

Although spinal metastasis from solid tumors has been amply reported in many literatures, little is known about spinal involvements of hematological malignancies. In this study, the authors analyzed patients with hematological malignancies involving the spine at a single institute to assess the epidemiologic data and their clinical courses.

\section{MATERIALS AND METHODS}

From January 2011 to September 2014, 195 patients (98 males, 97 females) suffered from hematological malignancies in a single institute were enrolled in this study. All patients referred to spine department due to spine-related symptoms. Their clinical records and radiological data were reviewed retrospectively. Plain radiographs and magnetic resonance imaging (MRI) were performed to evaluate the levels of spinal lesions causing their symptoms in all patients. Presenting symptoms and its causing spinal problems were analyzed using clinical history, imaging findings, and operation-related record in surgical cases. Proper treatment modalities were selected based on the status of the disease by experienced spine surgeons. In surgically treated patients, their clinical results were also analyzed. Numeric rating score (NRS) for pain and Oswestry disability index (ODI) was used for clinical results. Neurologic outcomes were assessed using Frankel grading for the patients who had neurologic compromise. The data were expressed as mean \pm standard deviation.

\section{RESULTS}

\section{Primary hematological malignancies}

Ninety-eight male patients and ninety-seven female patients were enrolled in this study. The mean age at the time of referral was $58.9 \pm 13.0$ years (21-93 years). The mean duration of follow-up after the diagnosis of spinal involvement of hematological malignancy was $23.5 \pm 15.6$ months (6-50 months). Primary diagnosis of hematological malignancies was multiple myeloma (96 patients, 49.2\%), chronic myeloid leukemia (30 patients, $15.4 \%$ ), acute myeloid leukemia (22 patients, $11.3 \%$ ), lymphoma (15 patients, 7.7\%), myelodysplastic syndrome (10 patients, 5.1\%), acute lymphoblastic leukemia (4 patients, 2.1\%), and others (18 patients, 9.2\%) (Fig. 1).

\section{Presenting symptoms and diagnosis of the spinal problems}

Presenting symptoms were classified into three types : axial pain, radiating pain, and extremity weakness combined with paresthesia. Mechanical axial pain (131 patients, 67.2\%) was the most common symptom, followed by radiating pain (49 patients, $25.1 \%$ ) and weakness (15 patients, 7.7\%) (Fig. 2).

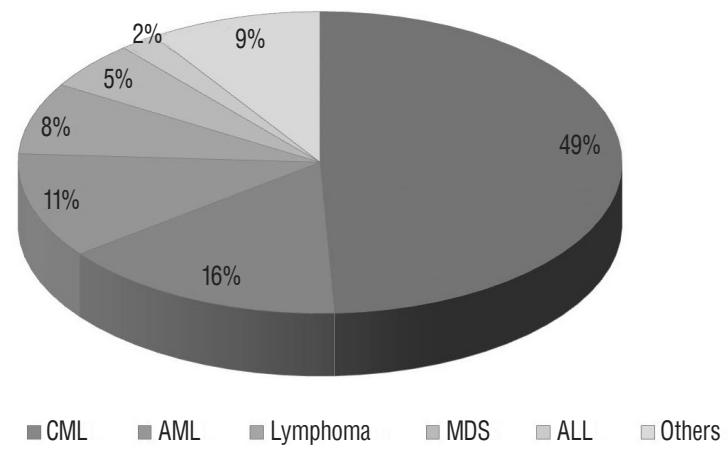

Fig. 1. Distribution of primary hematological malignancies. Multiple myeloma is the leading cause of hematologic malignancies causing spinal problems. Chronic myeloid leukemia and acute myeloid leukemia followed sequentially. MM : multiple myeloma, CML : chronic myeloid leukemia, AML : acute myeloid leukemia, MDS : myelodysplastic syndrome, ALL : acute lymphocytic leukemia.

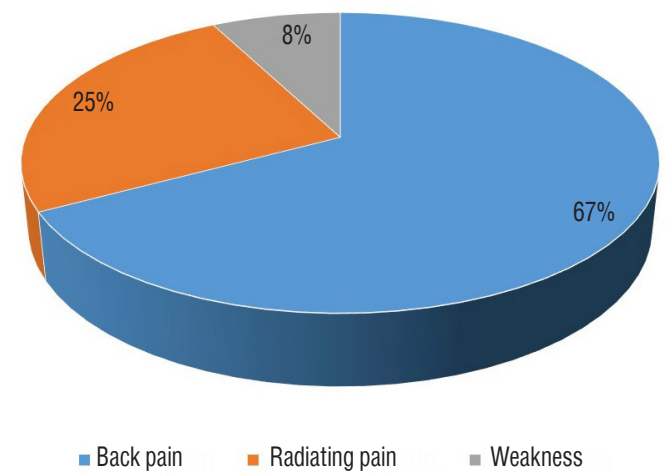

Fig. 2. Presenting symptoms in patients with spinal problems accompanied by hematological malignancies. Mechanical back pain related to pathological fracture was the main presenting symptom. Neurologic compromise as a presenting symptom was noted in $8 \%$ of this cohort. 
Pathologic spinal compression fracture was the leading cause of the axial pain, and the majority of the pathologic fractures were related to multiple myeloma (112 patients). Radiating pain was caused by the underlying degenerative spinal problems (44 patients) and drug-induced neuropathy (5 patients). Diagnosis of drug-induced neuropathy was done by clinical features (non-dermatomal paresthesia) and radiologic find-

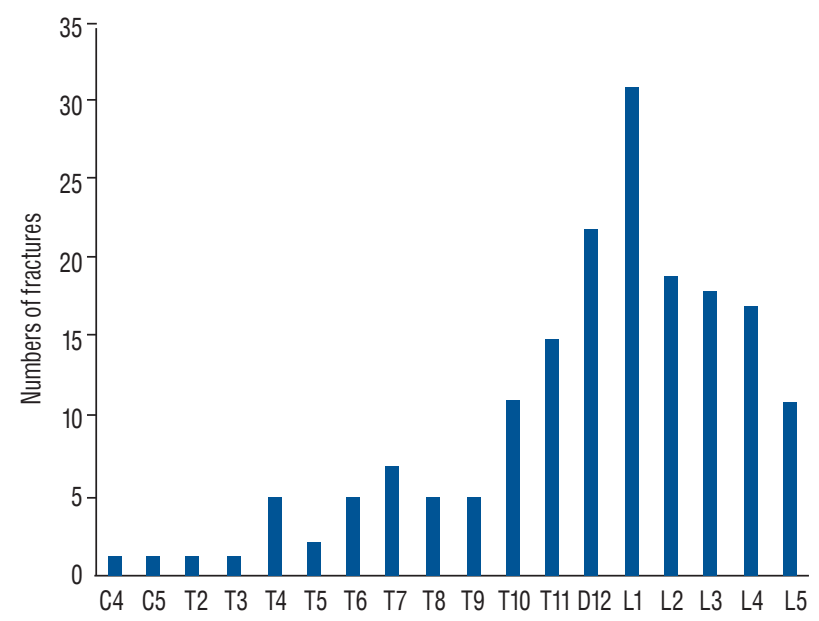

Fig. 3. Distribution of the involved vertebrae. Thoracolumbar and lumbar were the mainly affected sites for the pathologic lesions related to hematologic malignancies. ings (no evidence of compressive radiculopathy/myelopathy). Progressive extremity weakness resulted from epidural mass without pathologic fractures in 5 patients (4 with multiple myeloma and 1 with chloroma from acute myeloid leukemia) and pathologic fracture causing cord compression in 10 patients.

\section{Surgical managements and results}

Among the patients presenting pathologic fractures without neurologic compromises, 35 patients (26.5\%) who were unresponsive to conservative treatment for pain relief were surgically treated by percutaneous bone cement augmentation. The thoracolumbar area was the most involved site of these pathologic fractures (Fig. 3). And this surgical treatment was efficient for early pain management with similar long term clinical results (NRS and ODI) comparing with the conservative managements ${ }^{9}$. Instability of the fractured segment was evaluated based on the Spinal Instability Neoplastic Score (SINS) ${ }^{8)}$. A score of 7 to 12 denoted indeterminate instability (possibly impending) and 13 to 18 denoted instability. Surgery was recommended for patients with SINS scores $\geq 7$ with clinical features. Reconstructive surgery was performed in 16 patients $(6$ patients presenting impending cord compression and 10 patients presenting compressive myelopathy) (Fig. 4). There were
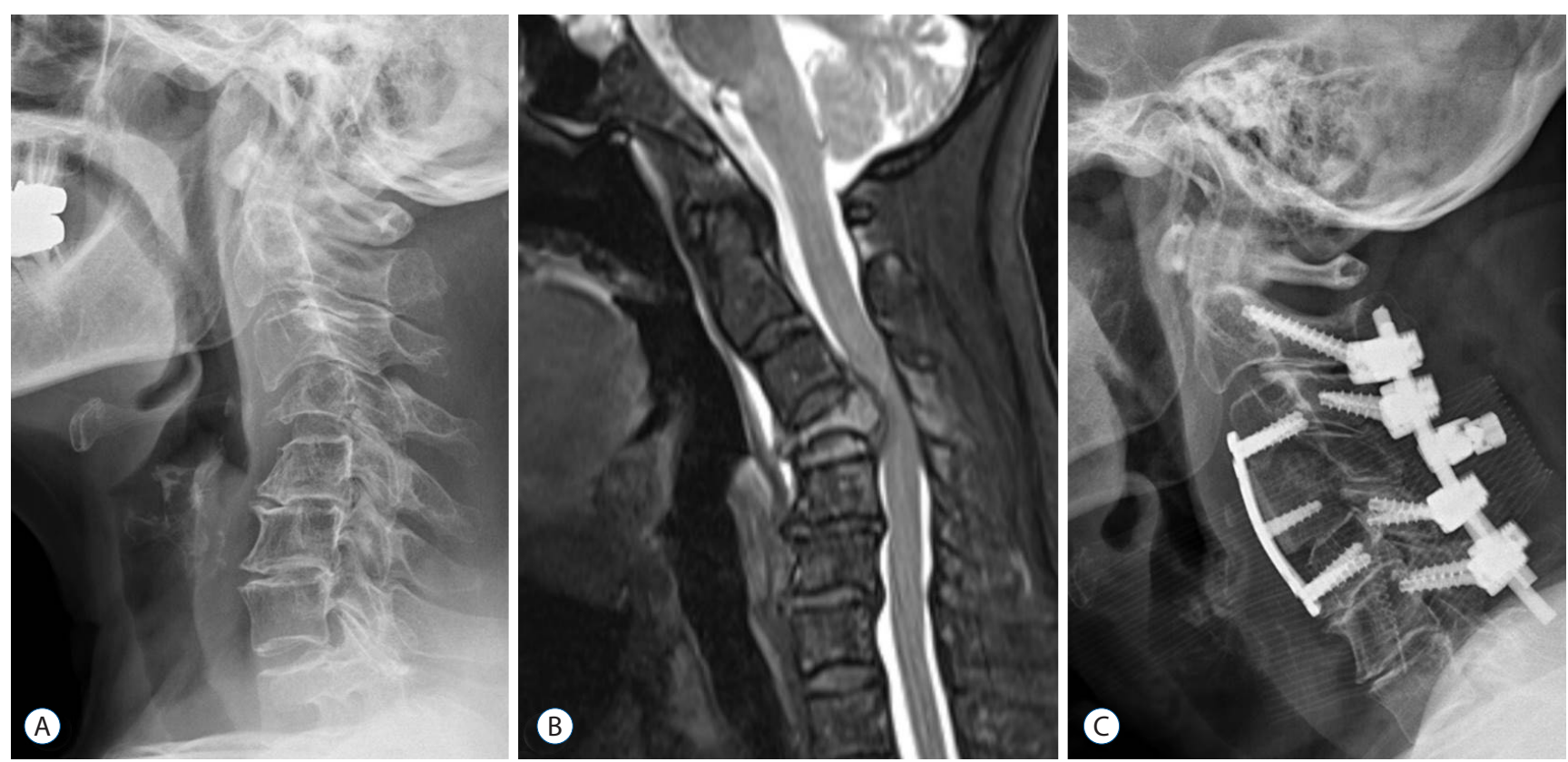

Fig. 4. A representing case required reconstructive surgery. A 71-year-old woman presented neck pain with progressive myelopathic symptoms. Plain radiograph (A) and fat suppression magnetic resonance imaging (B) show pathologic fracture at $C 4$ with epidural extension. Preoperative diagnostic work-ups including computed tomography guided biopsy revealed multiple myeloma. Decompressive and reconstructive surgery was performed (C). 
no surgery-related perioperative complications. In one patient, however, relapse of epidural mass developed at the adjacent level at the early postoperative period. In terms of neurologic outcomes, their neurologic outcomes were favorable in the patients with preoperative grade of Frankel grade D or E. However, the patients with preoperative grade of Frankel grade A or B presented poor neurologic recovery. Table 1 summarizes the characteristics of patients undergoing reconstructive surgical treatment.

\section{DISCUSSION}

Many patients with malignant tumors develop skeletal in- vasion, and the spine is the most frequent involved skeletal site $^{1)}$. As many as $70 \%$ of cancer patients have spinal metastasis, and up to $10 \%$ of those develop symptomatic spinal involvement ${ }^{4}$. Spinal metastasis usually comes from breast, lung, kidney, prostate, and thyroid. However, hematological malignancies, such as myeloma and lymphoma, also frequently involve the spine and neurologic complications can devel$\mathrm{op}^{2)}$. Their clinical manifestations are quite different from those of solid cancers. Compared to solid cancers which invade a focal area, hematologic malignancies usually involve skeletal system diffusely due to their hematopoietic and lymphoid origins and is more likely to develop intraspinal and extradural mass. Although metastasis of solid cancers has been amply investigated, little has been reported about spinal in-

Table 1. Summary of patients who underwent reconstructive surgeries

\begin{tabular}{|c|c|c|c|c|c|c|c|c|c|c|c|}
\hline Case & $\begin{array}{l}\text { Age/ } \\
\text { sex }\end{array}$ & $\begin{array}{l}\text { Primary } \\
\text { diagnosis }\end{array}$ & $\begin{array}{l}\text { Preop } \\
\text { Frankel }\end{array}$ & $\begin{array}{c}\text { Concomitant } \\
\text { pathologic } \\
\text { fracture }\end{array}$ & Level & $\begin{array}{l}\text { Epidural } \\
\text { mass }\end{array}$ & RT & $\begin{array}{l}\text { Surgical } \\
\text { treatment }\end{array}$ & $\begin{array}{l}\text { Last f/u } \\
\text { Frankel }\end{array}$ & Complications & Last f/u \\
\hline 1 & $39 / F$ & MM & A & Yes & L2 & Yes & Yes & D (C7-D2) & A & None & $\begin{array}{c}\text { DOD at PO } 2 \\
\text { months }\end{array}$ \\
\hline 2 & $57 / F$ & $\mathrm{MM}$ & $E$ & Yes & $\mathrm{T7}$ & No & Yes & $D+1$ & E & None & NED at $P O 5$ years \\
\hline 3 & $52 / \mathrm{M}$ & MM & A & No & $\mathrm{C} 6-\mathrm{T} 1$ & Yes & Yes & $D+1$ & A & $\begin{array}{l}\text { Relapse of } \\
\text { epidural mass }\end{array}$ & $\begin{array}{c}\text { DOD at PO } 3 \\
\text { months }\end{array}$ \\
\hline 4 & $67 / M$ & $\mathrm{MM}$ & A & Yes & $\mathrm{T7}$ & No & No & $D+1$ & A & None & Loss \\
\hline 5 & $41 / M$ & $\mathrm{MM}$ & $E$ & Yes & $\mathrm{T} 6$ & No & No & $D+1$ & $E$ & None & AWD at $P O 3$ years \\
\hline 6 & $53 / \mathrm{M}$ & $\mathrm{MM}$ & D & Yes & $\mathrm{T} 4$ & Yes & Yes & $D+1$ & E & None & $\begin{array}{l}\text { AWD at PO } 3 \\
\text { yeasrs }\end{array}$ \\
\hline 7 & $52 / F$ & MM & D & Yes & $\mathrm{L} 2, \mathrm{~L} 3$ & No & Yes & $\begin{array}{c}\mathrm{I} \\
\mathrm{VP}(\mathrm{L} 2,3)\end{array}$ & D & None & $\begin{array}{l}\text { DOD at PO } 1 \\
\text { month }\end{array}$ \\
\hline 8 & $58 / \mathrm{M}$ & MM & D & Yes & $\mathrm{T} 11$ & No & Yes & $D+1$ & $E$ & None & $\begin{array}{l}\text { DOD at PO } 18 \\
\text { months }\end{array}$ \\
\hline 9 & $60 / F$ & MM & E & Yes & C5 & No & No & $D+1$ & $E$ & None & AWD at PO 2 years \\
\hline 10 & $63 / M$ & $\mathrm{MM}$ & D & Yes & $\mathrm{T} 4$ & No & No & $D+1$ & $E$ & None & AWD at $P O 2$ years \\
\hline 11 & $56 / F$ & MM & D & Yes & $\begin{array}{l}\mathrm{T} 7, \mathrm{~T} 12, \\
\mathrm{~L} 1\end{array}$ & No & No & $\begin{array}{c}D+I(D 7) \\
\text { VP (D12, L1) }\end{array}$ & $\mathrm{E}$ & None & $\begin{array}{l}\text { AWD at PO } 20 \\
\text { months }\end{array}$ \\
\hline 12 & $43 / \mathrm{M}$ & AML & D & No & $\mathrm{T} 1-3$ & Yes & Yes & D & D & None & Loss \\
\hline 13 & $75 / M$ & MM & $E$ & Yes & $\mathrm{T} 5, \mathrm{~T} 10$ & No & No & $\begin{array}{l}\mathrm{D}+\mathrm{I}(\mathrm{D} 5) \\
\text { VP (D10) }\end{array}$ & $E$ & None & $\begin{array}{l}\text { AWD at PO } 18 \\
\text { months }\end{array}$ \\
\hline 14 & $55 / M$ & MM & $E$ & Yes & $\mathrm{T7}$ & No & Yes & $D+1$ & $E$ & None & $\begin{array}{l}\text { AWD at PO } 15 \\
\text { months }\end{array}$ \\
\hline 15 & $63 / M$ & MM & $E$ & Yes & L1 & Yes & Yes & $D+1$ & $E$ & None & $\begin{array}{l}\text { AWD at PO } 14 \\
\text { months }\end{array}$ \\
\hline 16 & $71 / F$ & $\mathrm{MM}$ & D & Yes & C4 & Yes & No & $D+1$ & D & None & AWD at $P O 2$ years \\
\hline
\end{tabular}

$\mathrm{RT}$ : radiotherapy, f/u : follow-up, $\mathrm{F}$ : female, $\mathrm{MM}:$ multiple myeloma, $\mathrm{D}:$ decompression, $\mathrm{DOD}:$ died of disease, $\mathrm{PO}$ : postoperative, I: instrumentation, NED : no evidence of disease, $M$ : male, AWD : alive with disease, VP : vertebroplasty, AML : acute myeloid leukemia 
volvement of hematological malignancies.

Hematological malignancies accounted for 9.4\% of new cancer diagnosis in the United States in 2014 and 3.9\% in South Korea in 2010. Leukemia is the most common hematological malignancy followed by lymphoma and myeloma ${ }^{18)}$. Many organs can be affected by hematological malignancies and bone is one of them. Representatively, multiple myeloma frequently involves the skeletal system in up to $90 \%$ of myeloma patients, but other hematological cancers can also affect bone $e^{2)}$.

Spinal involvement of hematological malignancies has various clinical manifestations. Although exact epidemiological data are scarce, clinicians often encounter various types of symptoms from nonspecific pain to definite neurologic deficits from radiculopathy, myelopathy, and direct nervous involvement of tumor cell in hematological malignancy patients.

Axial pain can originate from various sources including osteolysis, bone marrow infiltration, nervous system involvement, or the combination of the aforementioned mechanisms ${ }^{15)}$. Osteolysis is usually found in multiple myeloma, but has also been reported in non-Hodgkin's lymphoma, hairy cell leukemia, and chronic myeloid disorders in limited cas$\mathrm{es}^{5,11,13,14)}$. Osteolysis may result in fractures and skeletal instability. In this study, the most common site of pathologic fractures was the thoracolumbar junction. Because authors had not examined MRI of non-symptomatic patients with hematologic malignancies, it is unclear whether hematologic malignancies have some tropism. Authors thought that pathologic fractures, like benign compression fractures, are likely to occur in the thoracolumbar junction where mechanical stress concentrates. Bone marrow involvement by malignant cells produces pain by the expansion of hematopoietic matrix within the fixed volume causing elevated intraosseous pressure and impairment of blood supply ${ }^{15}$. Patients with pain from tumor infiltration of spine without neurologic deficit may benefit from steroid treatment, vertebroplasty, chemotherapy, and/or radiation therapy ${ }^{12)}$.

Radiating pain related to hematological malignancy results from the irritation of nerve root by tumor mass or fracture fragment and peripheral neuropathy due to chemotherapy agents ${ }^{3)}$. Many patients are elderly, so spondylotic neuropathy that is not from hematological origin can occur. In our study, 49 patients presenting radiating pain had various causes including spondylosis in 37 patients, pathologic fractures in 7 patients, epidural mass in 2 patients, and peripheral neuropathy in 3 patients.

Extramedullary epidural mass or fracture fragments may cause neurologic deficits ${ }^{7}$. In this study, 15 patients presented various degrees of paralysis of Frankel grade A to E. Spinal involvement of myeloma is most commonly treated non-surgically with a combination of radiotherapy and/or chemotherapy. When patients present with spinal instability or neurologic deficits in the setting of a compressive lesion, surgical intervention is considered ${ }^{7,19,21)}$. The surgical strategies are usually sufficient decompression of neural elements and/or stabilizing the spinal column. Stabilization via anterior or posterior fixation may also provide support for patients with hematological malignancies who are scheduled to undergo nonsurgical treatments to control disease progression. There are various surgical options depending on the degree of instability, compression of neural elements, and overall general health condition of the patient. Surgical management can improve neurologic function and quality of life $e^{6,20)}$. We performed reconstructive surgeries in 16 patients. Even though surgical intervention was useful for early paralysis (Frankel grade D or E), neurologic recovery was not satisfactory for the progressed paralysis (Frankel grade A).

Our study has several limitations. First, we enrolled only consulted patients in a single institute, so there is possibility of selection bias. Second, polyneuropathy as a causative factor was overlooked. Various chemotherapy agents produce polyneuropathy-induced pain to hematological malignancy patients. Third, clinical outcomes like visual analog scale and Oswestry Disability Index were not included.

However, this study demonstrated the various causes of the spine related problems in hematological malignancies, and these problems could develop by the disease progression or consequences of treatments. Moreover, neurologically deteriorating conditions could occur in limited cases (7.7\%) and timely surgical management may be required for these patients to improve the patients' quality of life and overall clinical outcomes.

\section{CONCLUSION}

Hematological malignancies may lead to various spinal problems ranging from fractures to spinal cord injury. Con- 
servative and palliative treatments are mainstay for these lesions. However, timely surgical interventions should be also considered for rapidly progressive neurologic compromise.

\section{- Acknowledgements}

This research was supported by Basic Science Research Program through the National Research Foundation of Korea (NRF) funded by the Ministry of Education (2015R1D1A 1A01060817). This study was reviewed and approved by institutional review board (IRB approval No. KC15RISI0477).

\section{References}

1. Bickels J, Dadia S, Lidar Z : Surgical management of metastatic bone disease. J Bone Joint Surg Am 91 : 1503-1516, 2009

2. Bladé J, Rosiñol L : Complications of multiple myeloma. Hematol Oncol Clin North Am 21 : 1231-1246, xi, 2007

3. Cavaletti G, Jakubowiak AJ : Peripheral neuropathy during bortezomib treatment of multiple myeloma: a review of recent studies. Leuk Lymphoma 51 : 1178-1187, 2010

4. Choi D, Crockard A, Bunger C, Harms J, Kawahara N, Mazel C, et al. : Review of metastatic spine tumour classification and indications for surgery: the consensus statement of the Global Spine Tumour Study Group. Eur Spine J 19 : 215-222, 2010

5. Dürr HR, Müller PE, Hiller E, Maier M, Baur A, Jansson V, et al. : Malignant lymphoma of bone. Arch Orthop Trauma Surg 122 : 10-16, 2002

6. Dürr HR, Wegener B, Krödel A, Müller PE, Jansson V, Refior HJ : Multiple myeloma: surgery of the spine: retrospective analysis of 27 patients. Spine (Phila Pa 1976) 27 : 320-324; discussion 325-326, 2002

7. Flouzat-Lachaniette $\mathrm{CH}$, Allain J, Roudot-Thoraval F, Poignard A : Treatment of spinal epidural compression due to hematological malignancies: a single institution's retrospective experience. Eur Spine J 22 : 548555,2013

8. Fourney DR, Frangou EM, Ryken TC, Dipaola CP, Shaffrey Cl, Berven SH, et al. : Spinal instability neoplastic score: an analysis of reliability and validity from the spine oncology study group. J Clin Oncol 29 : 3072-
3077, 2011

9. Ha KY, Min CK, Seo JY, Kim YH, Ahn JH, Hyun NM, et al. : Bone cement augmentation procedures for spinal pathologic fractures by multiple myeloma. J Korean Med Sci 30 : 88-94, 2015

10. Hage WD, Aboulafia AJ, Aboulafia DM : Incidence, location, and diagnostic evaluation of metastatic bone disease. Orthop Clin North Am 31 : 515-528, vii, 2000

11. Hameed A, Brady JJ, Dowling P, Clynes M, O'Gorman P : Bone disease in multiple myeloma: pathophysiology and management. Cancer Growth Metastasis $7: 33-42,2014$

12. Kaloostian PE, Yurter A, Zadnik PL, Sciubba DM, Gokaslan ZL : Current paradigms for metastatic spinal disease: an evidence-based review. Ann Surg Oncol 21 : 248-262, 2014

13. Lal A, Tallman MS, Soble MB, Golubovich I, Peterson L : Hairy cell leukemia presenting as localized skeletal involvement. Leuk Lyhmphoma 43 : 2207-2211, 2002

14. Muta T, Osaki K, Yamano Y : Translocation t(9;22) (p23;q11) in atypical chronic myeloid leukemia (aCML) presenting osteolytic lesions. Int J Hematol 76 : 344-348, 2002

15. Niscola P, Arcuri E, Giovannini M, Scaramucci L, Romani C, Palombi F, et al. : Pain syndromes in haematological malignancies: an overview. Hematol J 5 : 293-303, 2004

16. Popescu M, Popov V, Popescu G, Dobrea C, Sandu A, Grigorean VT, et al. : Spinal involvement with spinal cord compression syndrome in hematological diseases. Rom J Morphol Embryol 53 : 1069-1072, 2012

17. Recht $L$, Mrugala M : Neurologic complications of hematologic neoplasms. Neurol Clin 21 : 87-105, 2003

18. Rodriguez-Abreu D, Bordoni A, Zucca E : Epidemiology of hematological malignancies. Ann Oncol 18 Suppl 1 : i3-i8, 2007

19. Tomita K, Kawahara N, Kobayashi T, Yoshida A, Murakami H, Akamaru $\mathrm{T}$ : Surgical strategy for spinal metastases. Spine (Phila Pa 1976) 26 : 298-306, 2001

20. Utzschneider $S$, Schmidt $H$, Weber $P$, Schmidt GP, Jansson V, Durr HR : Surgical therapy of skeletal complications in multiple myeloma. Int Orthop 35 : 1209-1213, 2011

21. Zadnik PL, Goodwin CR, Karami KJ, Mehta Al, Amin AG, Groves ML, et al. : Outcomes following surgical intervention for impending and gross instability caused by multiple myeloma in the spinal column. J Neurosurg Spine $22:$ 301-309, 2015 